Jpn. J. Med. Sci. Biol., 48, 89 - 101, 1995.

\title{
MECHANISM OF CHLORAMPHENICOL-INDUCED MODULATION OF MOUSE ILEAL MOTILITY
}

Purushottam PRAMANIK and Chandan MITRA1

Department of Physiology, Jhargram Raj College, Midnapore, West Bengal, and 1 Department of Physiology, Presidency College, Calcutta, India

(Received December 27, 1994. Accepted April 24, 1995)

SUMMARY: The effect of chloramphenicol (CAP) on the intestinal motility of mice was studied. Acute and chronic CAP treatment significantly increased the food transit time. CAP produced concentration-dependent inhibition of motility of the isolated ileum of mice. Prazosin, propranolol, atropine, ouabain and chlorpromazine all failed to modulate or counteract the CAP-induced inhibition of ileal motility. However, naloxone and hexamethonium slightly modified the inhibitory response of CAP. The inhibitory response of CAP was markedly counteracted by cystine, a guanylate cyclase inhibitor. CAP increased the activity of $\mathrm{Ca}++$ ATPase in the ileum in all experiments. Our results suggest that the CAPinduced inhibition of the intestinal motility is not mediated through adrenergic, cholinergic and cAMP or through inhibition of the electrogenic pump. Compared to thiamphenicol (TAP), CAP, with a p- $\mathrm{NO}_{2}$ group in its structure, exhibited more pronounced alteration of both intestinal motility and $\mathrm{Ca}++$-ATPase activity. We, therefore, suggest that greater inhibition of ileal motility induced by CAP is possibly a p-NO2-cGMP-Ca++-ATPase-mediated mechanism.

\section{INTRODUCTION}

Chloramphenicol (CAP) inhibits the intestinal smooth muscle (1). Such inhibition of the intestinal smooth muscle by CAP has been attributed to redistribution of tissue $\mathrm{Ca}++$ away from the contractile elements (2). Redistribution of tissue $\mathrm{Ca}++$ has been suggested to occur either through activation of plasma membrane $\mathrm{Ca}^{++}$-ATPase for efflux of intracellular $\mathrm{Ca}^{++}$or by sequestration of in- 
tracellular $\mathrm{Ca}^{+}+$through activation of $\mathrm{Ca}^{++}+$-ATPase of the endoplasmic reticulum system (3). Cyclic GMP (cGMP) has been reported to activate $\mathrm{Ca}++$ extrusion ATPase in the coronary smooth muscle cell and such activation is achieved through cGMP-dependent protein kinase which phosphorylates the pump (4). Vascular and non-vascular smooth muscle dilation by nitrocompounds has also been attributed to the activation of guanylate cyclase with a consequent increase in cGMP level (5). The CAP toxicity is mainly due to the $\mathrm{p}-\mathrm{NO}_{2}$ group as structural feature of CAP (6). CAP increased the activity of $\mathrm{Ca}^{++}-\mathrm{ATPase}$ in taeniae coli and inhibits the smooth muscle of taeniae coli through a p- $\mathrm{NO}_{2}$ cGMP-Ca + +-ATPase-mediated process (7). Endogenous nitric oxide (NO) inhibits the intestinal motility (8). Since CAP inhibits the intestinal smooth muscle, it may have an influence on the gastrointestinal motility. Literature survey, however, has failed to provide any evidence in this relation.

The purpose of the present study is to evaluate the action of CAP on motility of the ileum and to find out the structure-activity correlation between CAP and its analogue TAP in this context, if any.

\section{MATERIALS AND METHODS}

Reagents: Chloramphenicol, thiamphenicol, atropine, prazosin, propranolol, naloxone, hexamethonium, ouabain and chlorpromazine were obtained from Sigma Chemicals (St. Louis, MO, USA). Cystine was procured from E. Merck (Darmstadt, FRG).

Animals: Male BALB/c mice, weighing 20-25 g, were used in food transit time and intestinal motility studies. For the charcoal meal test, animals were divided into two groups, A (control) and B (experimental), consisting of five animals in each group. For chronic experiments, animals of both groups were maintained on a standard laboratory diet and 12 -hr light/dark schedule for 7 or 14 days. Animals of group 'B' were orally treated with CAP at a dose of $0.1 \mathrm{mg} / \mathrm{g} /$ day for 7 or 14 days. Animals of group 'A' were pair-fed with those of group 'B' so as to overcome impact of any altered food intake in the experimental group following drug treatment. For acute experiments, $1.6 \mathrm{mg}$ of CAP was administered orally to the animals of the experimental group, 45 min before the charcoal meal and animals of the control group were treated with the same volume of water. The dose of CAP for acute experiment was selected on the basis of the body-surface-area ratio between man and the mouse (9) from the average therapeutic dose of CAP as $1 \mathrm{~g}$ daily for a subject weighing $65 \mathrm{~kg}$. 
Charcoal meal test: Effect of CAP on the intestinal motility was studied indirectly by the charcoal meal test (10). After the treatment period was over, animals were fasted for $16 \mathrm{hr}$ and then anaesthetized with urethane $(1.7 \mathrm{mg} / \mathrm{g} . \mathrm{b} . \mathrm{wt}$.). Mice were given a charcoal meal (animal charcoal $12 \mathrm{~g}$, tragacanth $2 \mathrm{~g}$, and water $130 \mathrm{ml}$ ) at a dose of $0.5 \mathrm{ml}$ per mouse by gavage and sacrificed $15 \mathrm{~min}$ after administration. The abdomen was opened, and the small intestines from the pylorus to the ileocecal junction were excised and its length measured. The distance which the charcoal meal traveled was also measured and expressed as the percentage of the total length of the small intestines.

Direct recording of ileal motility: Effect of CAP on ileal motility was studied by direct recording of the movement of the isolated ileum on Grass polygraph (Type 79E). Male BALB/c mice (20-25 g) were sacrificed with a blow on the head. The ileum was isolated and placed in a physiological salt solution (PSS) having the following composition (in $\mathrm{mM}$ ): $\mathrm{NaCl}, 154 ; \mathrm{KCl}, 5.6 ; \mathrm{CaCl}_{2}, 2.2 ; \mathrm{NaHCO}_{3}, 6.0$; glucose, 5.55; $\mathrm{pH} 7.4$. A piece $(3-4 \mathrm{~cm})$ of the ileum was suspended in a 20 -ml organ bath containing PSS saturated with $95 \% \mathrm{O}_{2}$ and $5 \% \mathrm{CO}_{2}$ at $37 \mathrm{C}$. One end of the ileum was attached to the bottom of the organ bath and the other end connected with a silk thread to a force-displacement transducer (Type FT03): the movements were recorded on a Grass polygraph. To study the action of CAP on the ileal motility, the compound was added to the muscle bath after 5 min of normal recording. To ascertain the mechanism of the action of CAP, agents like prazosin, propranolol, atropine, naloxone, hexamethonium, ouabain, chlorpromazine and cystine were each added to the organ bath 5 min before CAP treatment.

$\mathrm{Ca}++$-ATPase activity: The ileal $\mathrm{Ca}++-\mathrm{ATPase}$ activity was measured according to the method of Ghijsen and Van Os (11). Two pieces of the ileum were isolated from the mouse intestines. One of these was used for estimating the control level of tissue $\mathrm{Ca}++-A T P a s e$ and the other for estimating any change in the activity of tissue $\mathrm{Ca}++-\mathrm{ATPase}$ after CAP treatment. After incubation in PSS with or without CAP for 15 min, the muscle strip was homogenized in Tris-HCl buffer ( $\mathrm{pH} 7.4$ ). The activity of $\mathrm{Ca}++$-ATPase was then estimated. Protein content of the homogenate used in the study was determined essentially by the method of Parkinson et al (12). Phosphate, liberated during the enzymic action, was determined by the method of Lowry and Lopez (13).

Statistical analysis: The results of the experiments of the charcoal meal test and the $\mathrm{Ca}++$-ATPase activity were expressed as mean \pm SD. Student's t test was used for statistical analysis of the values. Differences were considered significant if $\mathrm{p}<0.05$. 


\section{RESULTS}

\section{Effect of Chloramphenicol on Food Transit Time}

Table I shows the effect of acute and chronic (7 and 14 days) treatment of CAP on the food transit time in mice. These results indicate that acute treatment with CAP $(1.6 \mathrm{mg})$ significantly $(\mathrm{p}<0.001)$ prolonged the food transit time as it reduced the distance of travel of charcoal meal by about $48 \%$. Chronic treatment with $\mathrm{CAP}(0.1 \mathrm{mg} / \mathrm{g} / \mathrm{day})$ for 7 and 14 days also prolonged the food transit time as it reduced the distance of travel of charcoal meal by about $33 \%$ and $19 \%$, respectively.

\section{Effect of Chloramphenicol on Motility of Ileum}

Figure 1 shows the concentration-dependent inhibitory effect of CAP on motility of the isolated ileum. The concentrations which produced minimum and maximum inhibition was $0.045 \mu \mathrm{mol} / \mathrm{ml}$ and $0.72 \mu \mathrm{mol} / \mathrm{ml}$, respectively.

\section{Effect of Chloramphenicol on Ileal Motility in the Presence of Prazosin}

Figure 2a shows the effect of CAP on the motility of the isolated ileum in the presence and absence of prazosin, an $\alpha$-adrenergic receptor blocker. The results of these experiments show that prazosin $(0.002 \mu \mathrm{mol} / \mathrm{ml})$ failed to modulate the inhibitory response of CAP on the ileal motility.

\section{Effect of Chloramphenicol on Ileal Motility \\ in the Presence of Propranolol}

Effect of CAP on the motility of the isolated ileum of mice in the absence and presence of propranolol, a $\beta$-adrenergic receptor blocker, is shown in Fig. $2 \mathrm{~b}$. The results of such experiments show that propranolol $(0.1 \mu \mathrm{mol} / \mathrm{ml})$ failed to modulate the inhibitory effect of CAP on the motility of the isolated ileum.

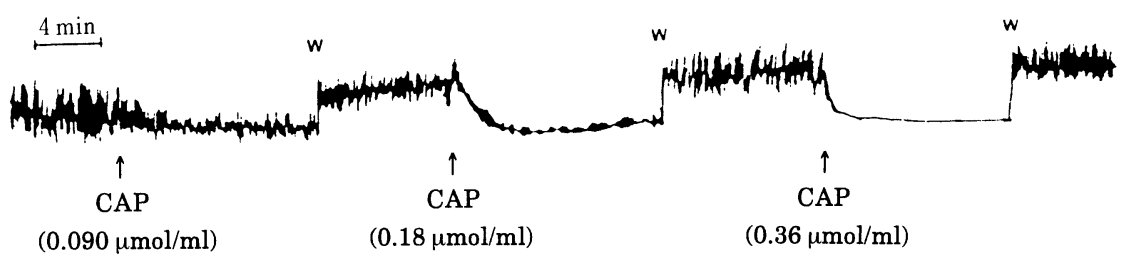

Fig. 1. Effect of chloramphenicol (CAP) on the motility of the isolated ileum of mice. Arrows represent the administration of drugs in the bathing medium and "W" represents the washing. 


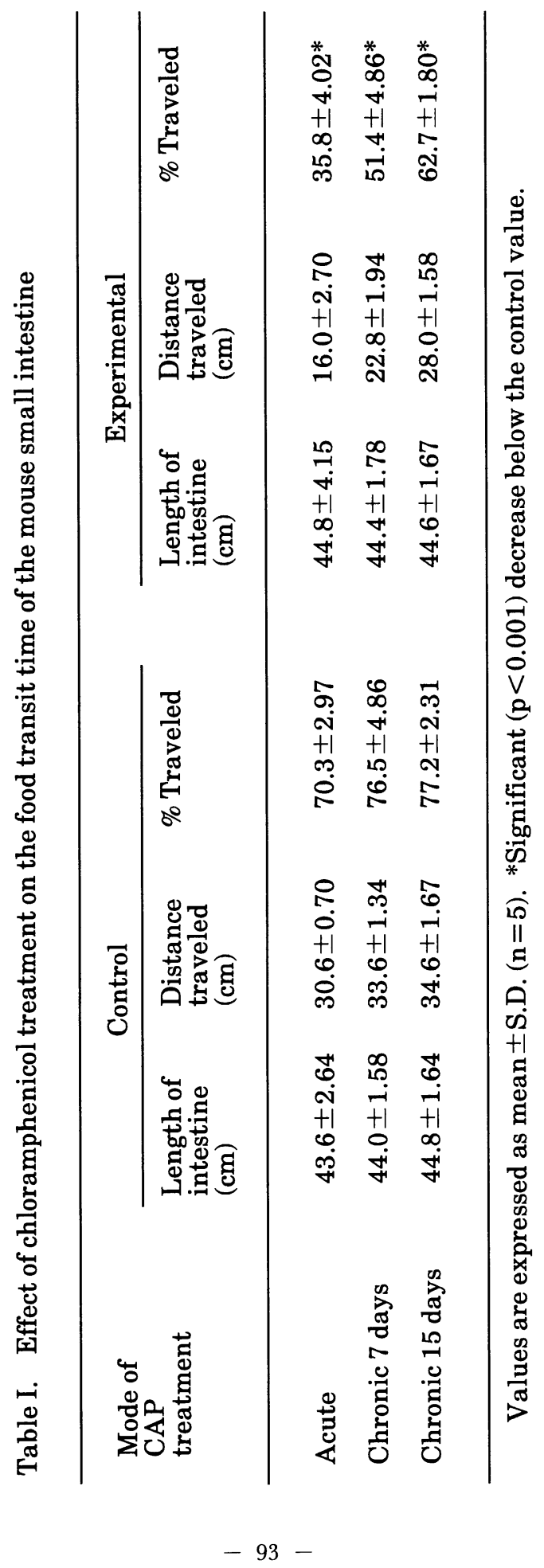



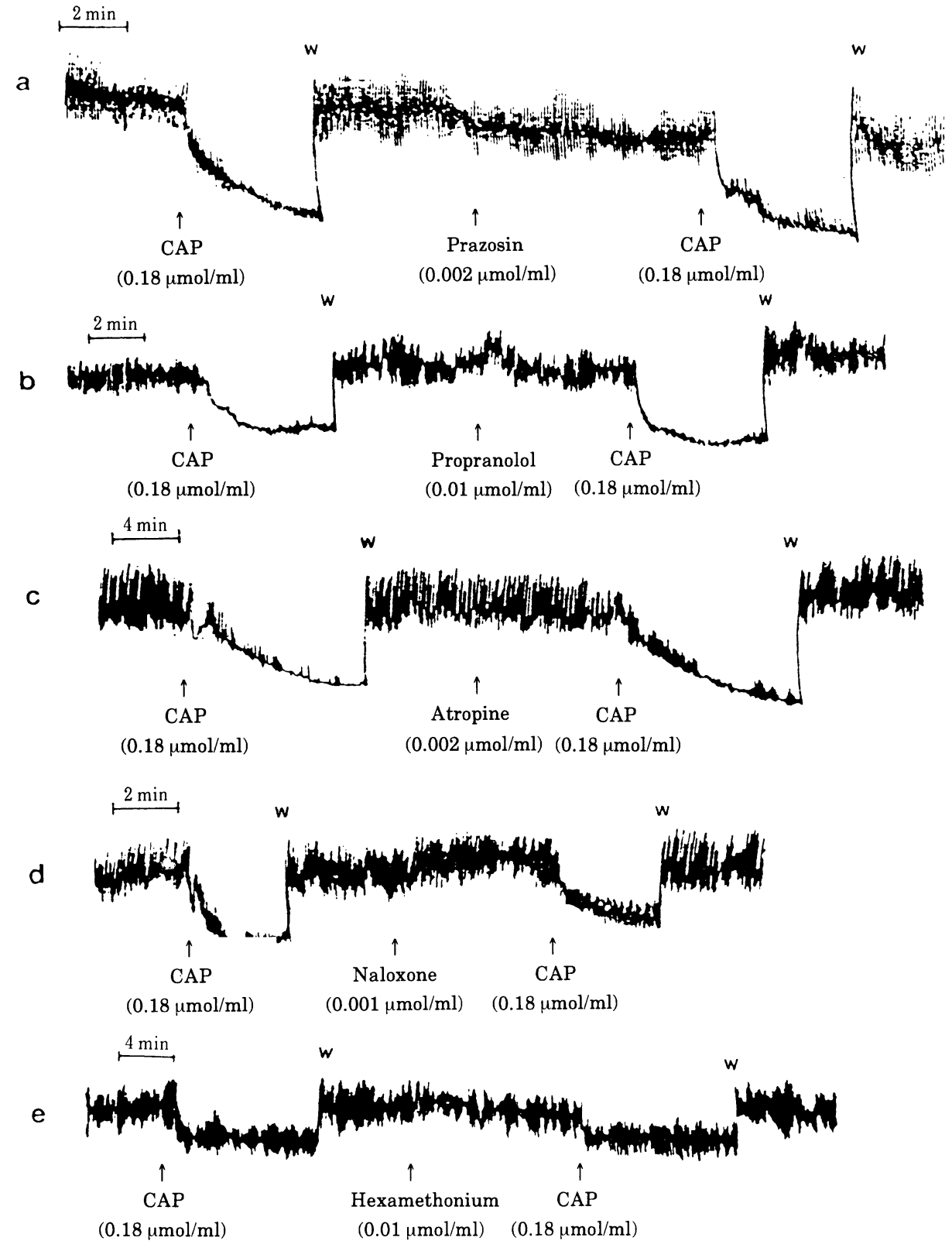

Fig. 2. Effects of chloramphenicol (CAP) on the motility of the isolated ileum of mice in the absence and presence of prazosin (a), propranolol (b), atropine (c), naloxone (d) and hexamethonium (e). Arrows represent the administration of drugs in the bathing medium and " $\mathrm{W}$ " represents the washing. 
Effect of Chloramphenicol on Ileal Motility in the Presence of Atropine

Figure 2c shows the effect of CAP on the motility of the isolated ileum in the presence of a muscarinic receptor blocker, atropine. Atropine, $0.002 \mu \mathrm{mol} / \mathrm{ml}$, failed to modulate the inhibitory effect of CAP on ileal motility.

\section{Effect of Chloramphenicol on Ileal Motility in the Presence of Naloxone}

To ascertain whether CAP-induced inhibition of the ileal motility is an opiate receptor-mediated mechanism or not, a group of experiments were performed with isolated ileum in the presence and absence of naloxone, an opiate antagonist. Figure 2d shows the effect of CAP on the motility of the isolated ileum in the presence of naloxone. Naloxone $(0.001 \mu \mathrm{mol} / \mathrm{ml})$ in all experiments slightly modulated the response of CAP.

\section{Effect of Chloramphenicol on Ileal Motility in the Presence of Hexamethonium}

Effect of CAP on the motility of the isolated ileum in the absence and presence of hexamethonium is shown in Fig. 2e. A ganglionic transmission blocker, hexamethonium $(0.01 \mu \mathrm{mol} / \mathrm{ml})$, in all experiments also slightly modulated the response of CAP.

\section{Effect of Chloramphenicol on Ileal Motility in the Presence of Ouabain}

Figure 3 shows the effect of CAP on the motility of the isolated ileum in absence and presence of ouabain, an inhibitor of $\mathrm{Na}+-\mathrm{K}+-\mathrm{ATPase}$. The results of such experiments clearly show that ouabain $(0.02 \mu \mathrm{mol} / \mathrm{ml})$ failed to modulate the inhibitory effect of CAP on the ileal motility as no significant difference of response was observed in the presence or absence of ouabain.

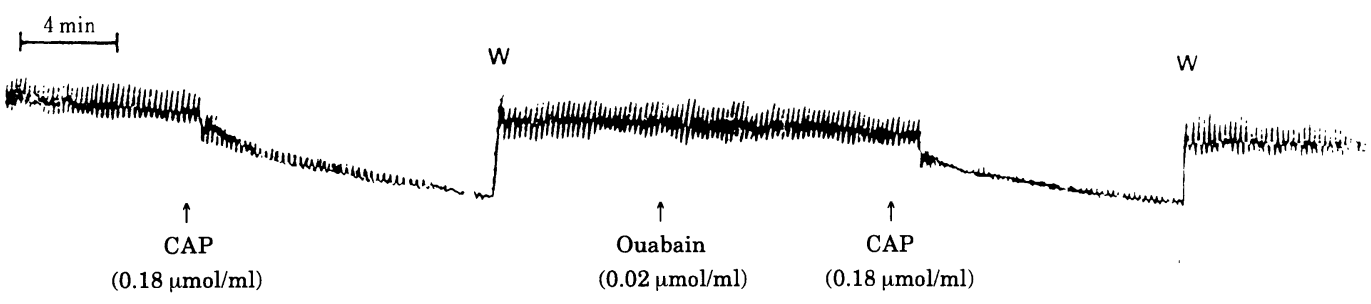

Fig. 3. Effect of chloramphenicol (CAP) on the motility of the isolated ileum of mice in the absence and presence of ouabain. Arrows represent the administration of drugs in the bathing medium and " $\mathrm{W}$ " represents the washing. 


\section{Effect of Chloramphenicol on Ileal Motility \\ in the Presence of Chlorpromazine}

To ascertain whether CAP-induced inhibition of the ileal motility is a cAMP mediated mechanism or not, a group of experiments were performed with the isolated ileum of mice in the presence or absence of chlorpromazine, an adenylate cyclase inhibitor. Figure 4a shows the effect of CAP on the ileal motility in the presence of chlorpromazine. Chlorpromazine $(0.002 \mu \mathrm{mol} / \mathrm{ml})$, in all experiments with the ileum failed to modulate the inhibitory action of CAP as no significant difference of response was observed in the presence or absence of this compound.
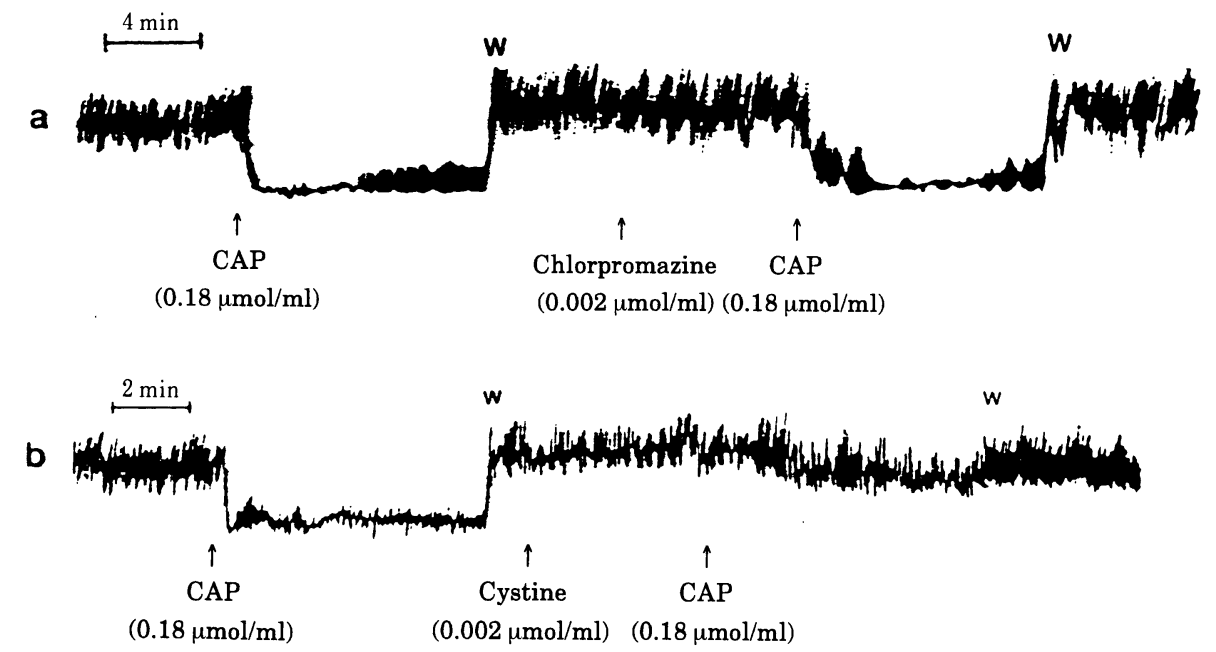

Fig. 4. Effects of chloramphenicol (CAP) on the motility of the isolated ileum of mice in the absence and presence of chlorpromazine (a) and cystine (b). Arrows represent the administration of drugs in the bathing medium and "W" represents the washing.

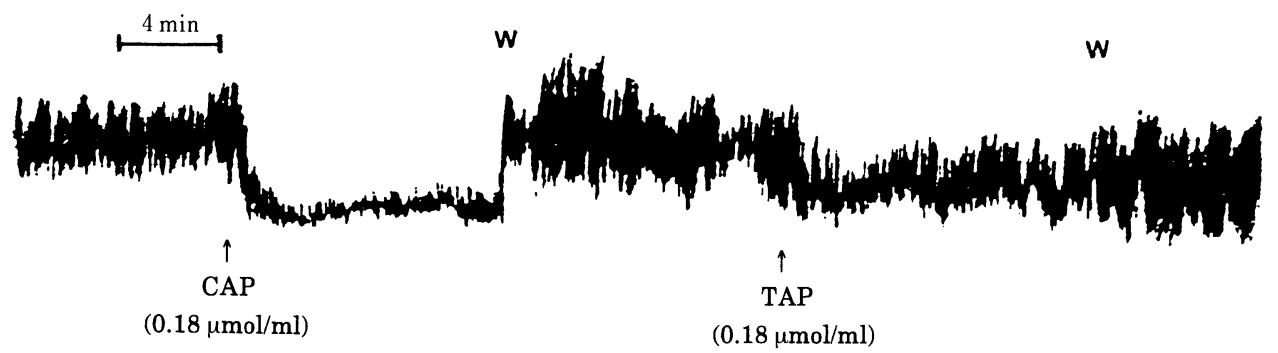

Fig. 5. Effect of chloramphenicol (CAP) and thiamphenicol (TAP) on the motility of the isolated ileum of mice. Arrows represent the administration of drugs in the bathing medium and "W" represents the washing. 
Effect of Chloramphenicol on Ileal Motility in the Presence of Cystine

Figure $4 \mathrm{~b}$ shows the effect of CAP on the motility of the isolated ileum in the presence and absence of cystine, a guanylate cyclase inhibitor. Prior addition of cystine $(0.002 \mu \mathrm{mol} / \mathrm{ml})$ significantly counteracted the inhibitory effect of CAP on the ileal motility.

\section{Effect of Chloramphenicol and Thiamphenicol on Ileal Motility}

To find the structure-activity correlation, a group of experiments were performed on the isolated ileum with CAP and its analogue TAP. Figure 5 shows the effect of CAP and TAP on the motility of the isolated ileum. The results indicate that TAP, like CAP, produces inhibition of motility of the ileum, but the degree of inhibition by TAP was much less than that by CAP.

\section{Effect of CAP on $\mathrm{Ca}++-A T P a s e$ Activity}

Table II summarizes the effect of CAP on the activity of $\mathrm{Ca}++-\mathrm{ATPase}$ in the mouse ileum. CAP was found to increase the activity of $\mathrm{Ca}++$-ATPase in a concentration-dependent manner and the responses at all concentration levels were significantly $(\mathrm{p}<0.001)$ different from control values.

Table III summarizes the effect of CAP and TAP on the activity of $\mathrm{Ca}++$ ATPase in the mouse ileum. CAP was found to increase $\mathrm{Ca}++$-ATPase activity at a more significant level $(p<0.001)$ than did TAP $(p<0.05)$ at the same concentration.

Table II. Effect of chloramphenicol (CAP) on the activity of $\mathrm{Ca}++-\mathrm{ATPase}$ in the mouse ileum

\begin{tabular}{llc}
$\begin{array}{l}\text { CAP concentration } \\
(\mu \mathrm{mol} / \mathrm{ml})\end{array}$ & $\mathrm{Ca}++$-ATPase activity & \% of control \\
\hline Without CAP & $0.010 \pm 0.002$ & 100 \\
0.045 & $0.011 \pm 0.002^{* *}$ & 110 \\
0.090 & $0.013 \pm 0.002^{*}$ & 130 \\
0.180 & $0.015 \pm 0.003^{*}$ & 150 \\
0.360 & $0.018 \pm 0.004^{*}$ & 180 \\
\hline
\end{tabular}

Values are expressed as mean \pm S.D. $(n=6) . \mathrm{Ca}++$-ATPase activity is expressed as phosphate liberation in $\mathrm{mmol} / \mathrm{g}$ protein/min at $37 \mathrm{C}$. ${ }^{*} \mathrm{p}<0.001 ;{ }^{* *} \mathrm{p}<0.01$. 
Table III. Effect of chloramphenicol (CAP) and thiamphenicol (TAP) on the activity of $\mathrm{Ca}++$-ATPase in the mouse ileum

\begin{tabular}{lcc}
\hline $\begin{array}{l}\text { Additions } \\
(\mu \mathrm{mol} / \mathrm{ml})\end{array}$ & Ca++-ATPase activity & \% of control \\
\hline Control & $0.0100 \pm 0.0020$ & 100 \\
$\operatorname{CAP}(0.180)$ & $0.0150 \pm 0.0030^{*}$ & 150 \\
$\operatorname{TAP}(0.180)$ & $0.0107 \pm 0.0020^{* *}$ & 107 \\
\hline
\end{tabular}

Values are expressed as mean \pm S.D. $(n=6) . \mathrm{Ca}++$-ATPase activity is expressed as phosphate liberated in $\mathrm{mmol} / \mathrm{g}$ protein/min at $37 \mathrm{C}$. ${ }^{*} \mathrm{p}<0.001 ;{ }^{* *} \mathrm{p}<0.05$.

\section{DISCUSSION}

The results of our experiments indicate that CAP induces significant decrease in the rate of passage of charcoal meal both in acute and chronic experiments (Table I) and thereby indirectly increased the food transit time. These results suggest that CAP, both in acute and chronic experiments, inhibits the intestinal motility.

To ascertain the role of CAP on the intestinal motility, a group of experiments were performed on the isolated ileum of mice. The results of these experiments indicate that CAP concentration-dependently inhibited the normal motility of the isolated ileum (Fig. 1). Prazosin (an $\alpha$-adrenergic receptor blocker), propranolol (a $\beta$-adrenergic receptor blocker), and atropine (a muscarinic receptor blocker) all failed to modulate or counteract the inhibitory response of CAP on the ileal motility (Fig. 2a,b,c). The results of these experiments clearly suggest that CAP-induced inhibition of the ileal motility is not through any one of the above tested mechanisms. The CAP-induced inhibition of the ileal motility is not through either the electrogenic pump or cAMP as ouabain (an Na+-K+-ATPase inhibitor) and chlorpromazine (a cAMP inhibitor) failed to modulate or counteract the inhibitory response of CAP (Figs. 3 and 4a). However, the results of the experiments with naloxone (an opiate antagonist) and hexamethonium (a 
ganglionic transmission blocker) suggest that both these mechanisms possibly have a slight counteracting influence on CAP-induced inhibition of the intestinal motility (Fig. 2d,e).

The chloramphenicol toxicity is mainly due to $\mathrm{p}-\mathrm{NO}_{2}$ group (6). NO has been proposed as the mediator of non-adrenergic and non-cholinergic relaxation of the ileum and stomach of the guinea pig $(14,15)$ and the stomach, colon, duodenum and ileum of the rat (16-18). Calignano et al. (8) proposed that endogenous NO plays a role in the modulation of in vivo intestinal motility. Our results indicate that CAP-induced inhibition of the ileal motility is due to the $\mathrm{p}-\mathrm{NO}_{2}$ group as structural feature of CAP, since significant inhibition was not observed with TAP, an analogue of CAP devoid of $\mathrm{p}-\mathrm{NO}_{2}$ group (Fig. 5). Earlier we also reported that CAP-induced inhibition of the smooth muscle is due to $\mathrm{p}-\mathrm{NO}_{2}$ group (7).

A causal relationship exists between the increase in cGMP levels and the relaxation of the vascular smooth muscle, particularly by nitro-compounds (4). Nonvascular and vascular smooth muscle dilation by nitro-compounds has also been attributed to the activation of guanylate cyclase with a consequent increase in the cGMP level (5). To ascertain whether CAP-induced inhibition of the ileal motility is a cGMP-mediated mechanism, a group of experiments were performed on the isolated ileum in the presence of cystine, a guanylate cyclase inhibitor (19). The results of these experiments suggest that the CAP-induced inhibition of the ileal motility is a cGMP-mediated mechanism since inhibitory response of CAP is significantly counteracted by cystine (Fig. 4b).

Cyclic GMP has also been reported to activate sarcolemmal $\mathrm{Ca}++$ extrusion ATPase in the coronary smooth muscle cells and such activation is achieved through cGMP-protein kinase which phosphorylates the pump (4). To ascertain whether CAP-induced inhibition of the ileal motility is a $\mathrm{Ca}++$ ATPase-mediated mechanism, the effect of CAP on Ca++-ATPase activity was studied. The results of our experiments indicate that CAP concentrationdependently increased $\mathrm{Ca}++$-ATPase activity (Table II). Compared to CAP, the degree of TAP-induced stimulation of $\mathrm{Ca}++$ ATPase activity is much less (Table III), suggesting that there exists a structure-activity correlation between CAP and TAP, in relation to ileal motility and $\mathrm{Ca}^{++}+$-ATPase activity.

In summary, it is suggested that CAP inhibits the intestinal motility and such inhibition is not mediated through mechanisms like adrenergic, cholinergic and cAMP or through inhibition of the electrogenic pump. In addition, it is suggested that CAP-induced inhibition of the intestinal motility is possibly a $\mathrm{p}-\mathrm{NO}_{2}$ cGMP-Ca ++-ATPase mediated mechanism. 


\section{ACKNOWLEDGEMENTS}

The authors wish to thank the University Grants Commission (UGC), India, for the financial support of this work.

\section{REFERENCES}

1. Banerjee, S. and Mitra, C. (1976): Muscle relaxation properties of chloramphenicol. J. Pharm. Sci., 65, 705-708.

2. von Breemen, C., Aaronson, A. and Lutzenhiser, R. (1978): $\mathrm{Na}+-\mathrm{Ca}++$ interactions in mammalian smooth muscle. Pharmacol. Rev., 30, 167-208.

3. Lotersztajn, S., Hanoune, J. and Pekcer, F. (1981): A high affinity $\mathrm{Ca}^{+}+$ stimulated $\mathrm{Mg}++$-dependent ATPase in rat liver plasma membrane. J. Biol. Chem., 256, 11209-11215.

4. Popescu, L. M., Panoiu, C., Hinescu, M. and Nutu, O. (1985): The mechanism of cGMP-induced relaxation in vascular smooth muscle. Eur. J. Pharmacol., 107, 393-394.

5. Waldman, S. A. and Murad, F. (1987): Cyclic GMP synthesis and functions. Pharmacol. Rev., 39, 163-196.

6. Yunis, A. a. (1988): Chloramphenicol: Relation of structure to activity and toxicity. Ann. Rev. Pharmacol. Toxicol., 28, 83-100.

7. Pramanik, P., Datta, S. C. and Mitra, C.(1994): Mechanism of inhibition of smooth muscle of guinea pig taenia coli by chloramphenicol. J. Physiol. Pharmacol., 45, 132-145.

8. Calignano, A., Whittle, B. J. R., Di Rosa, M. and Moncada, S. (1992): Involvement of endogenous nitric oxide in the regulation of rat intestinal motility in vivo. Eur. J. Pharmacol., 229, 273-276.

9. Ghosh, M. N. (1984): Fundamentals of experimental pharmacology, Scientific Book Agency, Calcutta. 154p.

10. Ghosh, M. N. (1984): Fundamentals of experimental pharmacology, Scientific Book Agency, Calcutta. 150p.

11. Ghijsen, W. E. J. M. and van Os, Ch. (1979): Ca++-stimulated ATPase in brush border and basolateral membranes of rat duodenum with high affinity sites for $\mathrm{Ca}++$. Nature, 279, 802-803.

12. Parkinson, D. K., Ebel, W., Dibona, D. R. and Sharp, W. G. (1972): Localization of the action of cholera toxin on the adenyl cyclase in mucosal epithelial cells of rabbit intestine. J. Clin. Invest., 51, 2292-2298.

13. Lowry, H. O. and Lopez, A. J. (1946): The determination of inorganic phosphate in the presence of labile phosphate esters. J. Biol. Chem., 162, 421428. 
14. Gustafsson, L. E., Wiklund, L. E., Wiklund, N. P., Persson, M. G. and Moncada, S. (1990): Modulation of autonomic neuroeffector transmission by nitric oxide in guinea pig ileum. Biochem. Biophys. Res. Comm., 173, 106110.

15. Desai, K. M., Sessa, W. C. and Vane, J. R. (1991): Involvement of nitric oxide in the reflex relaxation of the stomach to accomodate food or fluid. Nature, 351, 477-479.

16. Li, C. G. and Rand, M. J. (1990): Nitric oxide and vasoactive intestinal polypeptide mediated non-adrenergic and non-cholinergic inhibitory transmission to smooth muscle of the rat gastric fundus. Eur. J. Pharmacol., 191, 303-309.

17. Hata, F., Sing, T., Kanada, A., Yamano, N., Kataoka, T., Takeuchi, T. and Yagasaki, O. (1990): Essential role of nitric oxide in descending inhibition in the rat proximal colon. Biochem. Biophys. Res. Commun., 172, 14001406.

18. Kanada, S., Hata, F., Suthamnatopong, N., Maehera, T., Sing, T., Takeuchi, $\mathrm{T}$. and Yagasaki, O. (1992): Key role of nitric oxide and cyclic GMP in nonadrenergic and non-cholinergic inhibition in rat ileum. Eur. J. Pharmacol., 216, 287-292.

19. Brandwein, H. J., Lewicki, J. A.. and Murad, F. (1981): Reversible inactivation of guanylate cyclase by mixed disulfide formation. J. Biol. Chem., 256, 2958-2962. 